\title{
Experimental Analysis on Double Layer Kapton Material using Peltier Thermoelectric Device
}

\author{
AH Dahalan ${ }^{1,2}$, M.Z.A. Abd. Aziz ${ }^{1}$, M.A. Othman ${ }^{1}$ \\ ${ }^{1}$ Faculty of Electronic and Computer Engineering, Universiti Teknikal Malaysia Melaka \\ ${ }^{2}$ Faculty of Electrical and Electronic Engineering Technology, Universiti Teknikal Malaysia Melaka
}

\begin{tabular}{l} 
Article Info \\
\hline Article historys: \\
Received Jan 7, 2020 \\
Revised June 28, 2020 \\
Accepted June 30, 2020 \\
\hline
\end{tabular}

\section{Keywords:}

Kapton

Peltier Thermoelectric

Dielectric

Loss Tangent

Temperature

\begin{abstract}
Kapton is one of the flexible materials used in the development of microwave components for the telecommunications system. The electrical properties of Kapton are dependent on the material's temperature. In this study, this material will be heated, and the electrical properties of dielectric permittivity and loss tangent will be analyzed. This material heating process is done by using Peltier thermoelectric which is installed with Aluminium alloy. The $0 \mathrm{~V}$ up to 7 V DC voltage was supplied to the Peltier during the heating process. Then, the electrical properties of Kapton were measured by using a dielectric probe and vector network analyzer (VNA) at frequencies of $1 \mathrm{GHz}$ to $9 \mathrm{GHz}$. The results obtained show the Kapton temperature was increased from $27^{\circ} \mathrm{C}$ to $41^{\circ} \mathrm{C}$. Meanwhile, the dielectric permittivity also varied from 1.72 to 1.64 at the frequency of $5 \mathrm{GHz}$ when $4 \mathrm{~V}$ was used. The maximum loss tangent value of 0.5 was observed when the maximum DC voltage of $7 \mathrm{~V}$ was applied. The knowledge of this experimental work can be used to design reconfigurable microwave components for smart system applications

Copyright $\odot 2019$ Institute of Advanced Engineering and Science. All rights reserved.
\end{abstract}

\section{Corresponding Author:}

Abdul Halim Bin Dahalan,

Faculty of Electronic and Computer Engineering,

Universiti Teknikal Malaysia Melaka,

Hang Tuah Jaya, 76100 Durian Tunggal, Melaka, Malaysia

Email: abdulhalim@utem.edu.my

\section{INTRODUCTION}

In a telecommunication system, the application of flexible substrate is most popularly used in antenna design. One such material used is thin flexible polyimide substrate Kapton. Kapton is a material that is flexible and able to operate with very good flexibility over-temperature ranging from $\left(-73^{\circ} \mathrm{C}\right.$ to $\left.+400^{\circ} \mathrm{C}\right)[1]$. Kapton is a material that incorporates good mechanical properties, heat resistance, chemical resistance, and electrical properties when compared with other materials. Comparison with other material are shown in Table 1 below;

Table 1: Comparison with Other Materials [1]

\begin{tabular}{lccccc}
\hline \multicolumn{1}{c}{ Material } & PET & PEN & Kapton & LCP & Paper \\
\hline Mechanical properties & Good & Good & Excellent & Good & - \\
Heat resistance & Low & Very good & Excellent & Good & - \\
Chemical resistance & Good & Good & Good & Excellent & - \\
Electrical properties & Good & Good & Good & Good & Good \\
\hline
\end{tabular}

Where,

PET - Polyethylene terephthalate

PEN - Polyethylene naphthalate

LCP - Liquid crystal polymers 
There are many techniques to heat materials such as thermal chamber [2], chemical [3], induction heater [4], solar [5], Peltier thermoelectric [6][7] has been reported. Thermal chamber [2] technique, where the material will be heated through thermal chamber equipment with a temperature value of $25^{\circ} \mathrm{C}$ to $150^{\circ} \mathrm{C}$. Chemical technique [3] such as Magnesium (Mg)-based metal hydride system has potentially high-temperature heat storage which covers a temperature range from $250^{\circ} \mathrm{C}$ to $550^{\circ} \mathrm{C}$. The induction heater [4] also was applied to electric vehicles to generate heat by inputting electric power directly. Solar [5] also produced heat in the cooking system for families and institutions. It has two basic system components, solar collectors with reflectors and a cooking unit. Other researchers also applied Peltier for heat technique for food warmer and cooler with solar power [6]. Others designed heating and cooling jacket with microcontroller varying the temperatures from high to low depending on season[7].

Peltier thermoelectric is one of electronics product that can produce cooler or heater effect which is used in many applications such as refrigerator, air conditioner, power generation, etc [8]. In this experimental work, the heater side of Peltier was used to heat the material. The heat will be transferred to a conductive plate material such as Aluminium alloy. Aluminum is a good thermal conductor [9] in electrical and electronic design. Furthermore, the cost of Aluminium is cheaper when compared to copper material.

This paper will analyze the electrical properties of Kapton material such as dielectric permittivity $\left(\varepsilon_{r}\right)$ and loss tangent at frequencies of $1 \mathrm{GHz}$ up to $9 \mathrm{GHz}$. The heating process will use the Peltier thermoelectric device with a DC voltage from $0 \mathrm{~V}$ to $7 \mathrm{~V}$.

\section{RESEARCH METHOD}

\subsection{Description of experiment Design}

There are three materials have been used in this design work which is Kapton, Peltier thermoelectric and aluminum alloy plate. The Kapton and Aluminum alloy material thickness are $0.055 \mathrm{~mm}$ and $0.2 \mathrm{~mm}$ respectively. The heating process was done by using the Peltier thermoelectric model TEC1-12706 with a maximum temperature of $138^{\circ} \mathrm{C}[10]$. The experiment block design is shown in Figure 1 and Figure 2.

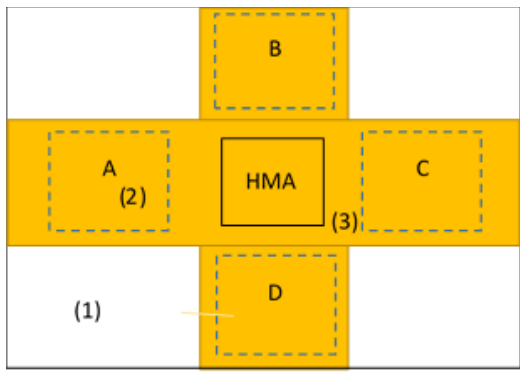

Note : (1) Aluminium plate

Figure 1. Experiment block design

(2) Peltier ( A,B,C\&D - back side)

(3) Kapton

* HMA - Heat measured area

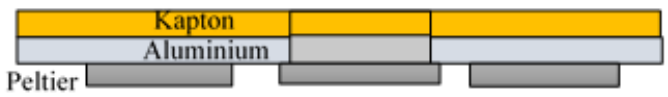

Figure 2. Experiment block design (side view)

The photo of prototype experimental design as shown in figure 3, where (a) is a front side view and (b) is a backside view.

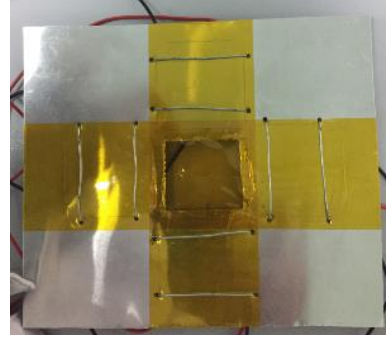

(a)

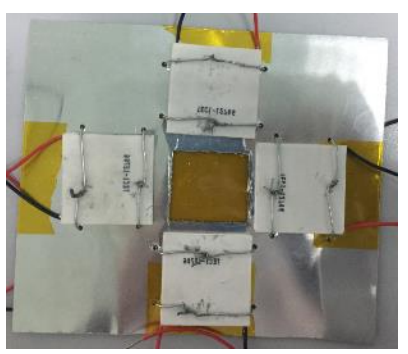

(b)

Figure 3. Photo of prototype experimental design 
There are three main analyses will be done based on this experimental work. First, the analysis of the correlation of temperature and applied DC voltage will be formulated. Secondly, the analysis of the dielectric changes on Kapton will be studied. This is due to the dielectric of the Kapton will be the effect when the temperature increases or decreases. Third, the analysis of the loss tangent versus temperature of the system will also be done.

\subsection{Experiment equipment's setup}

The types of equipment used in the experiment are (i) DC power supply (30V,2.5A), (ii) PNA-L Network Analyzer (Keysight N5232A), (iii) Dielectric probe kit (Agilent 85070 E) and (iv) RMS multimeter (Agilent).

All types of equipment are connected as shown in Figure 4. The calibration of the Network Analyzer will be performed first before the dielectric measurement been done. Then, the start and stop frequency of the Network Analyzer were set to $1 \mathrm{GHz}$ up to $10 \mathrm{GHz}$. While DC Voltage of $0 \mathrm{~V}$ to $7 \mathrm{~V}$ was set as the input voltage to the Peltier with a $0.5 \mathrm{~V}$ voltage increment. During the measurement process, the parameter of temperature, dielectric permittivity and tangent loss of the Kapton will be recorded. The measurement process was repeated 5 times to obtain accurate measured data. The temperature of the Peltier was set to room temperature before each measurement process started. This process was done by adopted 20 minutes of relaxing time right after every measurement process.
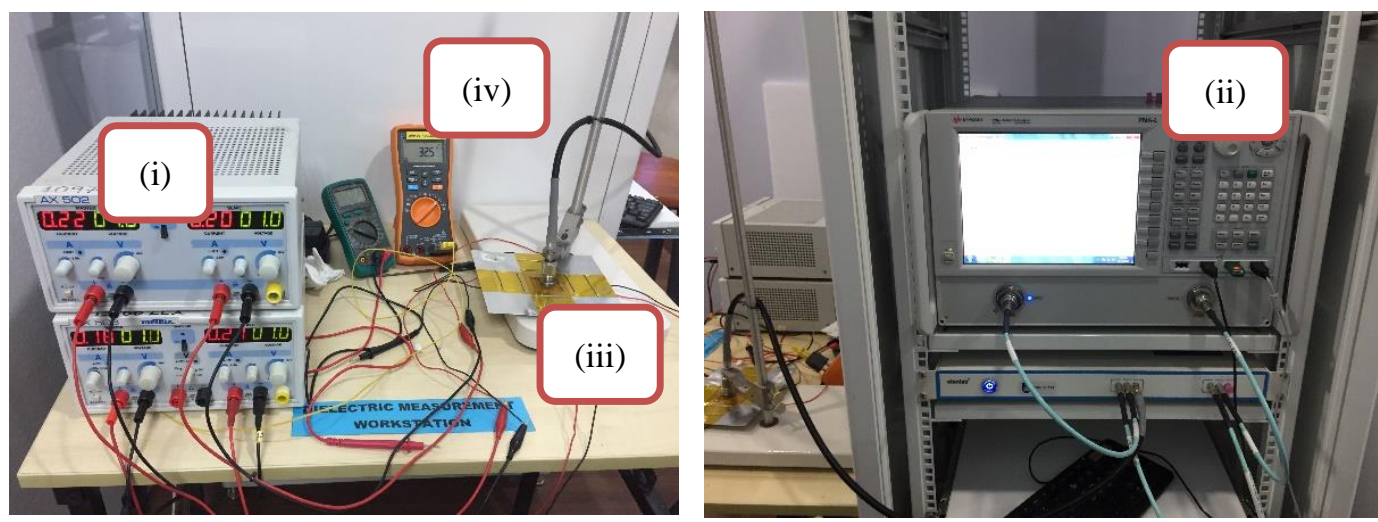

Figure 4. Equipment's experiment setup

\section{RESULTS AND ANALYSIS}

\subsection{Voltage and Temperature correlation}

The experiment result for voltage and temperature correlation is shown in Figure 5. The temperature was increased from $27^{\circ} \mathrm{C}$ to $41^{\circ} \mathrm{C}$ as the voltage increased from $0 \mathrm{~V}$ to $7 \mathrm{~V}$. When the voltage was supplied to the Peltier device, the heat will be produced and the temperature of the Kapton was increased. The higher heating temperature was achieved by using four-unit of Peltier.

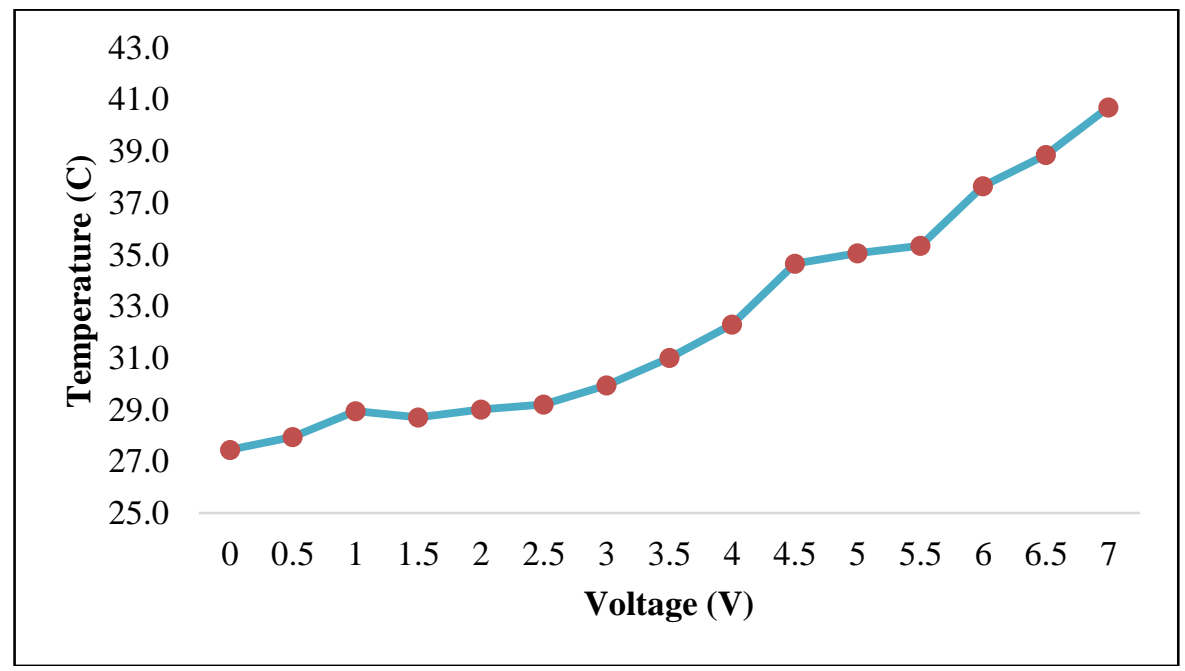

Figure 5. Voltage and Temperature correlation 


\subsection{Dielectric permittivity effect}

Kapton is a thin flexible polyimide substrate where the material has relative dielectric permittivity $\left(\varepsilon_{r}\right)$ and loss tangent $(\tan \delta)$. The dielectric permittivity of Kapton value changes according to the temperature range of $\left(-73^{\circ} \mathrm{C}\right.$ to $\left.+400^{\circ} \mathrm{C}\right)$. Therefore, the temperature of Kapton increased when the DC voltage supplied to the Peltier and Aluminium plate increased. At this stage, the dielectric permittivity of the Kapton also will be affected. The experiments result of dielectric permittivity versus frequency for Kapton is shown in Figure 6. When the voltage increased is from $0 \mathrm{~V}$ to $7 \mathrm{~V}$, the dielectric value was decreased from 1.38 to 0.20 . At a higher frequency of $9 \mathrm{GHz}$, the value of dielectric permittivity measured around 0.20 to 0.29 . While the dielectric permittivity value of 1.38 to 1.58 was measured at a frequency of $1 \mathrm{GHz}$.

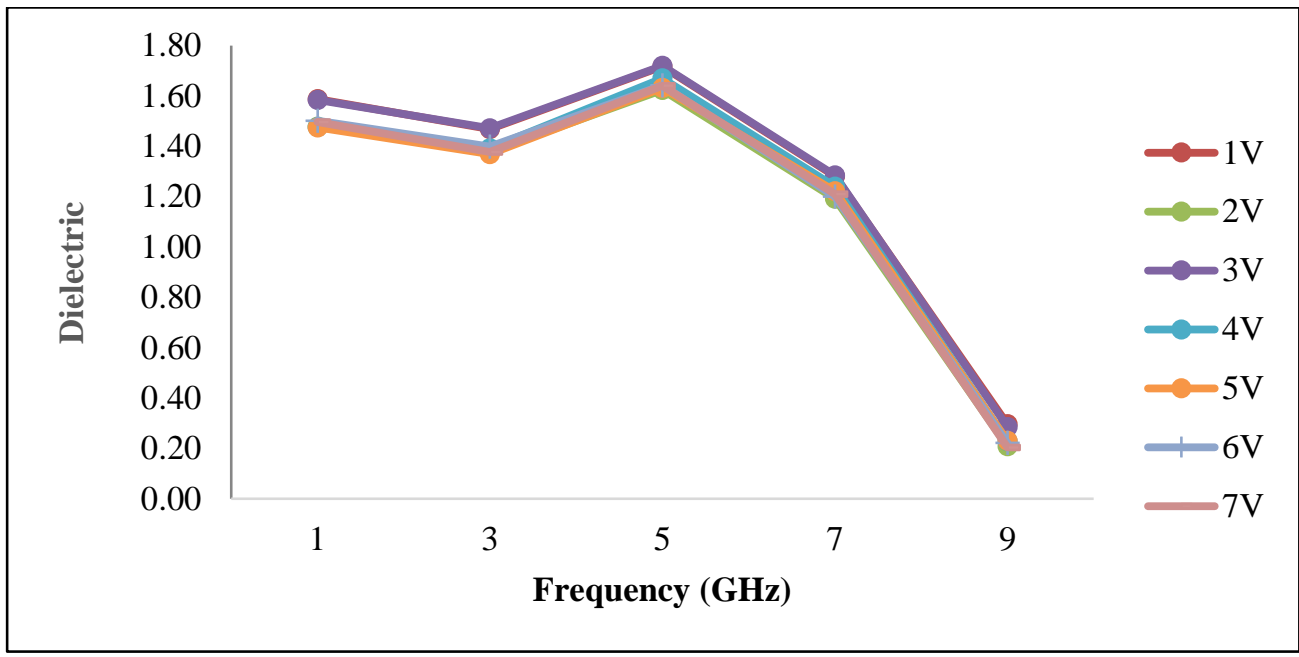

Figure 6. Dielectric permittivity versus frequency

The dielectric permittivity value also decreased when the DC voltage supply is increased. Figure 7 shows the dielectric permittivity value versus temperature of the Kapton. There is a small drop of dielectric permittivity value found at the temperature of $29^{\circ} \mathrm{C}$ for every frequency. Then, the dielectric permittivity value was increase between 1.285 up to 1.720 for the temperature of $30^{\circ} \mathrm{C}$. The highest dielectric permittivity was measured between 1.720 to 1.641 at the frequency of $5 \mathrm{GHz}$. While the lowest dielectric permittivity value was measured between 1.285 to 1.194 at the frequency of $7 \mathrm{GHz}$. The measurement result shows that the dielectric permittivity value is reduced as the frequency increased except for the frequency of $5 \mathrm{GHz}$.

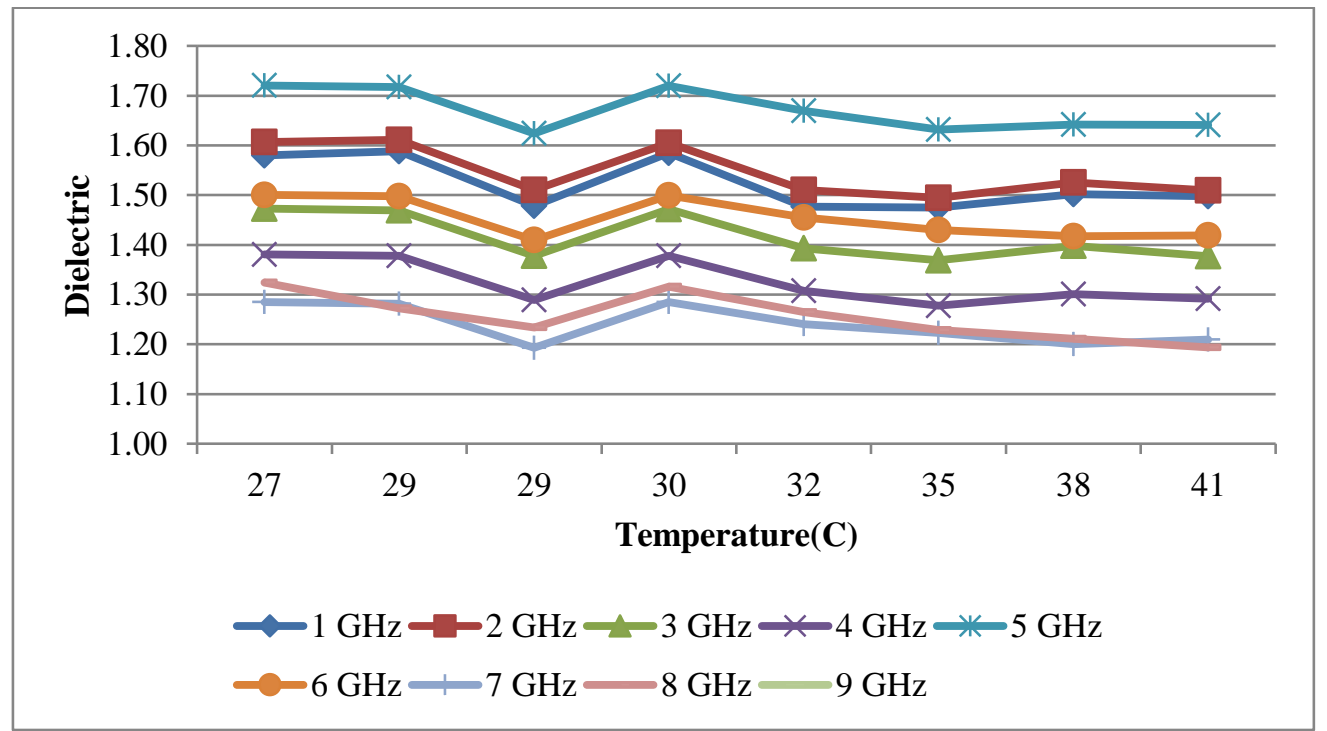

Figure 7. Dielectric permittivity versus temperature 


\subsection{Loss tangent effect}

The loss tangent is an important parameter that will present the electrical losses of the material. Figure 8 shows the loss tangent of Kapton versus frequency. The result shows that the loss tangent of the Kapton is lower than 0.5 . The loss tangent value is increased from 0.03 at frequency $1 \mathrm{GHz}$ up to 0.48 at a frequency of $9 \mathrm{GHz}$. There is an increment of 0.17 can be seen at frequency $9 \mathrm{GHz}$ when the DC voltage is increased from $1 \mathrm{v}$ to $7 \mathrm{~V}$. While, the increment of 0.16 can be seen at frequency $5 \mathrm{GHz}$ for all DC voltage values.

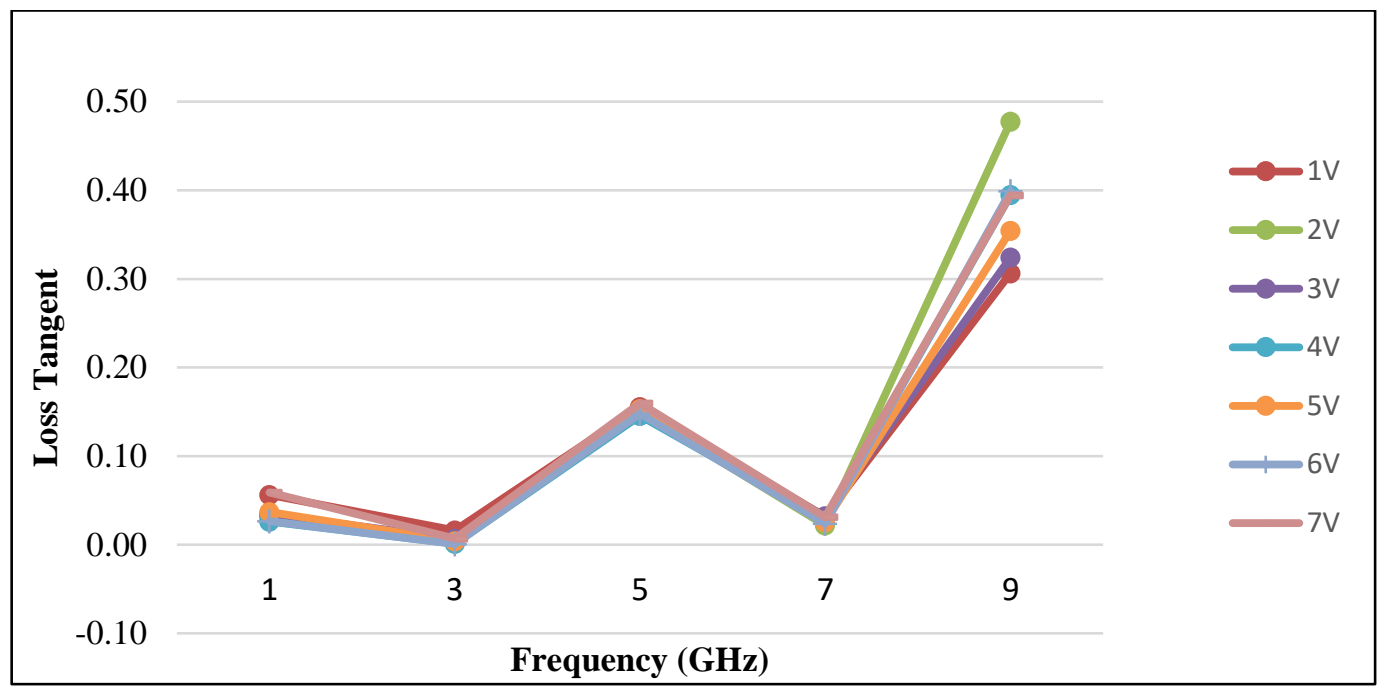

Figure 8. Loss Tangent versus frequency

Loss tangent value also increases when the DC voltage supply is given is increased. Figures 9 and 10 show the loss tangent versus temperature of Kapton. The loss tangent of Kapton at a frequency of $5 \mathrm{GHz}$ shows a small increment from 0.145 to 0.16 for the temperature of $27^{\circ} \mathrm{C}$ to $41^{\circ} \mathrm{C}$. While the small increment of 0.021 was also found for frequency $8 \mathrm{GHz}$. The highest value of loss tangent is 0.478 was measured at frequency $9 \mathrm{GHz}$ and temperature of $29^{\circ} \mathrm{C}$.

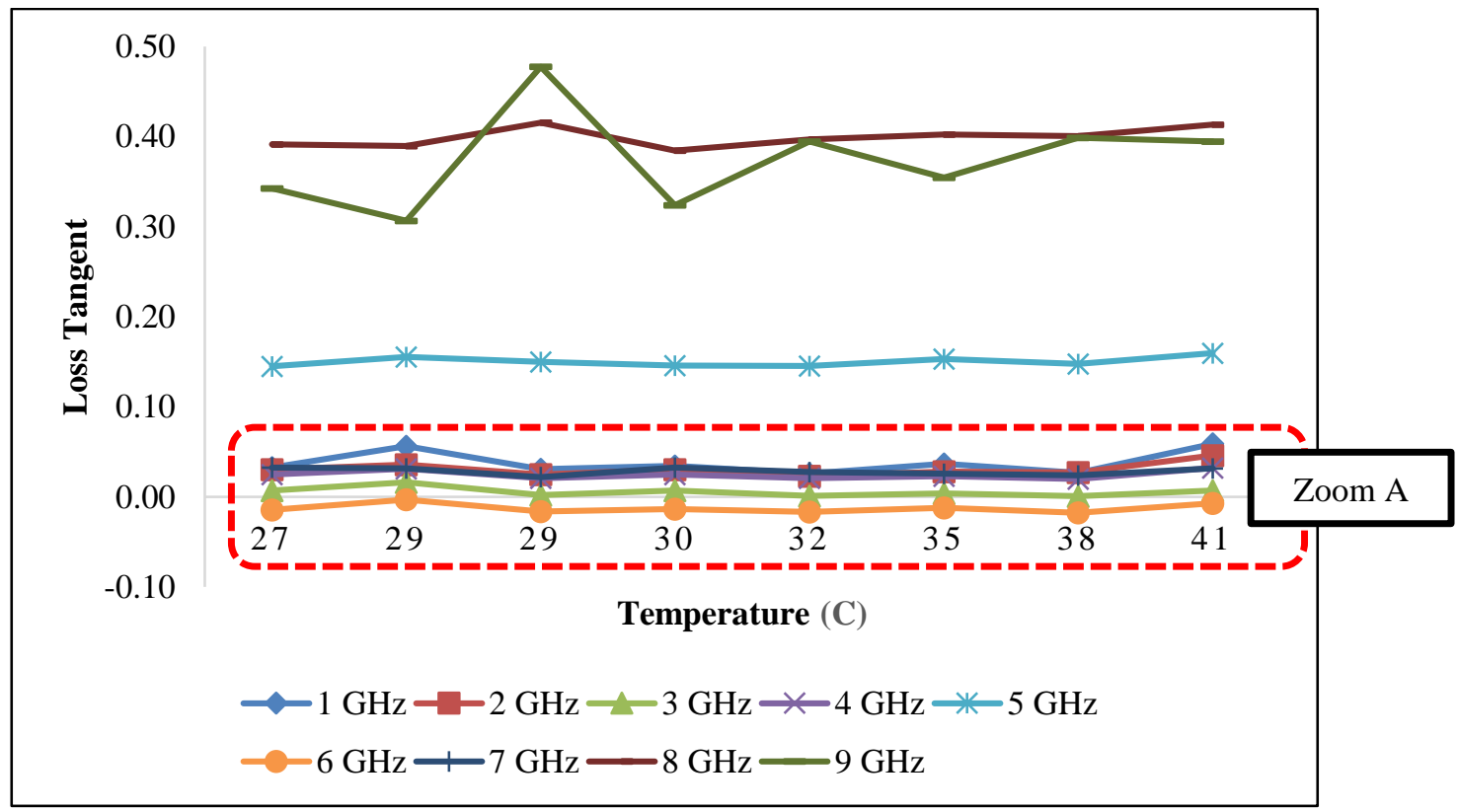

Figure 9. Loss Tangent versus temperature 


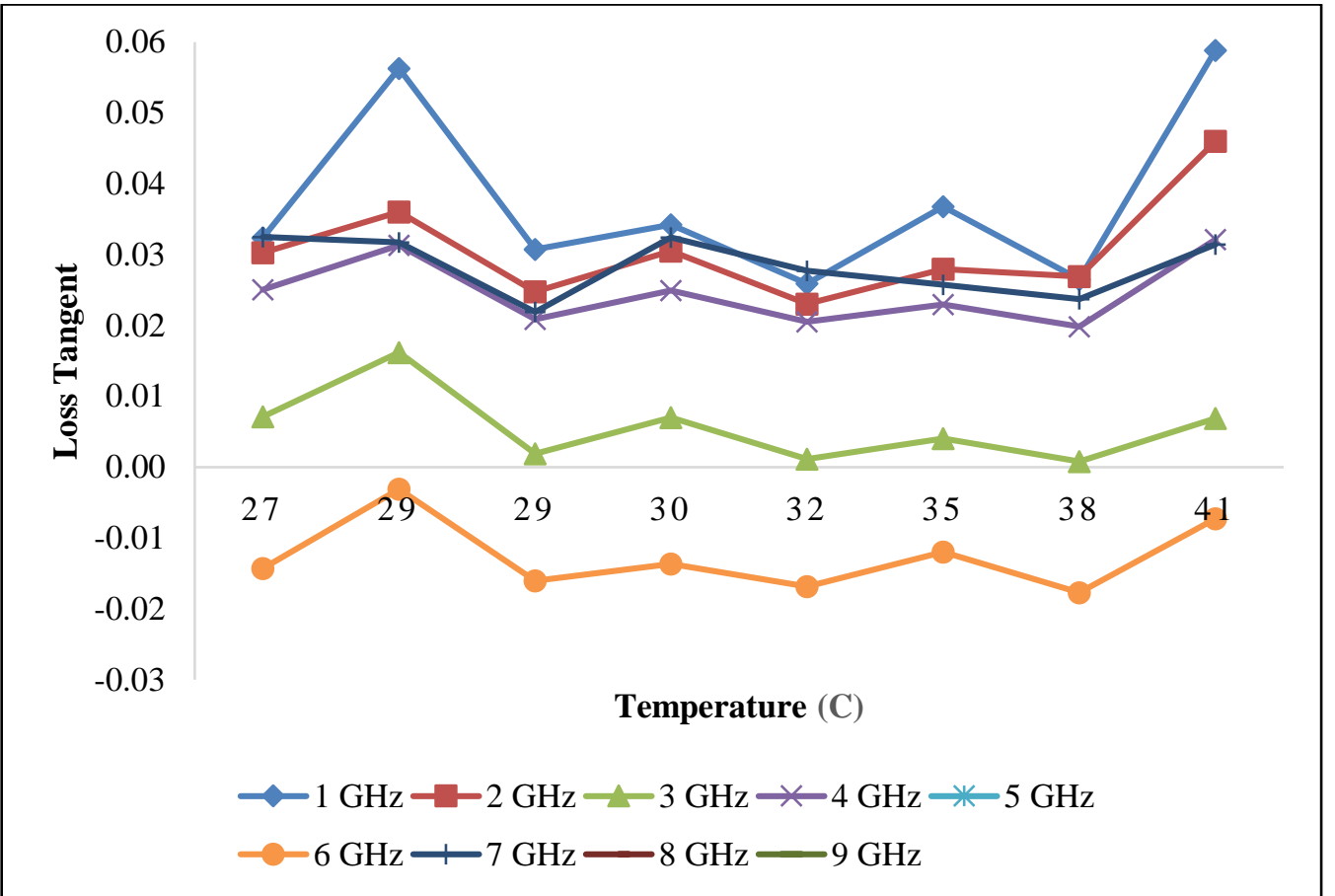

Figure 10. Loss Tangent versus temperature (Zoom A)

The loss tangent of other frequency was measured less than 0.06 towards all temperature values. The loss tangent for these frequency groups are found between -0.018 up to 0.06 . The graph for frequency $3 \mathrm{GHz}$ shows the tangent loss is close to 0 . While the graph for frequency $6 \mathrm{GHz}$ shows the loss tangent value lower than zero.

\section{CONCLUSION}

In this paper, the dielectric permittivity and loss tangent of Kapton was changed when the temperature of the material increased. Four units of Peltier were used to ensure the heating process of Kapton is uniform. The difference of 0.15 can be observed when the DC voltage supply is increased from $1 \mathrm{~V}$ to $7 \mathrm{~V}$. The 0.2 difference of loss tangent value was also recorded when a similar DC voltage supply was applied. These change characteristics can be used to design microwave components such as antennas or filters for smart systems applications.

\section{ACKNOWLEDGMENTS}

The authors would like to thank Universiti Teknikal Malaysia Melaka (UTeM) for supporting this research work under the grant PJP/2019/FKEKK-CETRI/CRG/S01650. We also would like to thank the Faculty of Electronics and Computer Engineering and Faculty of Electrical and Electronic Engineering Technology at UTeM for supporting this research.

\section{REFERENCES}

[1] Z. Yang, A. Takacs, S. Charlot, and D. Dragomirescu, "Design of Kapton based passive circuits at microwave frequencies," Eur. Microw. Week 2015 "Freedom Through Microwaves", EuMW 2015 Conf. Proceedings; 2015 45th Eur. Microw. Conf. Proceedings, EuMC, pp. 873-876, 2015

[2] Y. G. Rabobason, B. Ravelo, and N. Benjelloun, "Thermal empirical effect on the Kapton-based passive microstrip circuit," 2016 URSI Asia-Pacific Radio Sci. Conf. URSI AP-RASC 2016, pp. 1911-1914, 2016.

[3] A. Reiser, B. Bogdanović, and K. Schlichte, "Application of Mg-based metal-hydrides as heat energy storage systems," Int. J. Hydrogen Energy, vol. 25, no. 5, pp. 425-430, 2000.

[4] S.-H. Yu, D.-J. Park, and K.-C. Kim, "Heat Source Analysis of an Induction Heater for an Electric Vehicle," IEEE Trans. Magn., vol. 53, no. 6, pp. 1-4, 2017.

[5] K. Schwarzer and M. E. Vieira da Silva, "Solar cooking system with or without heat storage for families and institutions," Sol. Energy, vol. 75, no. 1, pp. 35-41, 2003.

[6] P. Attavane, "Solar powered portable food warmer and cooler based on Peltier effect," pp. 1975-1978, 2017. 
[7] J. R. Poikayil, J. Francis, D. Saju, A. Suresh, and J. Varghese, "Peltier Integrated Heating \& Cooling Jacket," pp. 260-263, 2017.

[8] S. B. Riffat and X. Ma, "Thermoelectrics: A review of present and potential applications," Appl. Therm. Eng., vol. 23, no. 8, pp. 913-935, 2003.

[9] D. D. Chung, "Materials for thermal conduction," Appl. Therm. Eng., vol. 21, pp. 1593-1605, 2001.

[10] "Specification of Thermoelectric module" http://www.peltiermodules.com/peletier.dataseheets/TEC112706.pdf

\section{BIOGRAPHY OF AUTHORS}

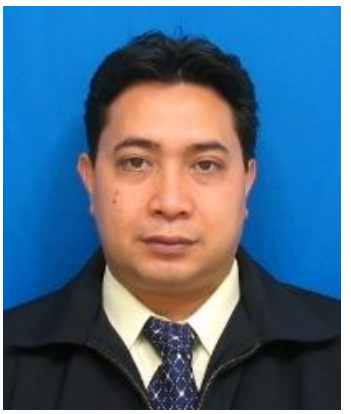

Abdul Halim Bin Dahalan is currently PhD student at the Faculty of Electronic and Computer Engineering, Universiti Teknikal Malaysia Melaka in Telecommunication field. He received Degree in Electrical Engineering (Communication) on 2002 from Universiti Teknologi Malaysia (UTM) and his master's in Electronic Engineering (Telecommunication System) from Univeriti Teknikal Malaysia Melaka (UTeM) on 2012. He is Lecturer at Faculty of Electrical and Electronic Engineering Technology at Universiti Teknikal Malaysia Melaka (UTeM).

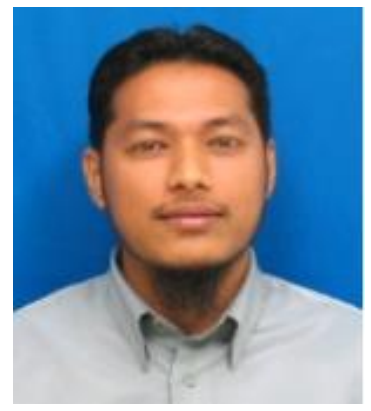

Mohd Zoinol Abidin Abd Aziz received Degree Bachelor of Engineering in Electrical Engineering from Universiti Teknologi Malaysia (UTM) on 2000. Then, he works as Research Assistant at UTM from 2000 till 2002. He received his master's degree and PHD in Electrical Engineering (Telecommunication) from UTM on 2005 and 2015 respectively. Currently, he is Lecturer at Faculty of Electronic and Computer Engineering at Universiti Teknikal Malaysia Melaka (UTeM).

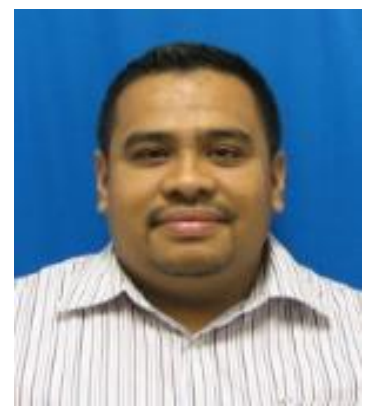

Mohd Azlishah Othman received Degree Bachelor of Engineering in Electrical Engineering (Telecommunication) from Universiti Teknologi Malaysia (UTM) on 2003. In September 2005 he joined Universiti Teknikal Malaysia Melaka (UTeM) as a Lecturer at Fakulti Kej. Elektronik dan Kej. Komputer (FKEKK). He received his Master's Degree in Computer and Communication Engineering from University of Nottingham, UK on 2005 and continues his $\mathrm{PhD}$ in Electrical and Electronic Engineering in University of Nottingham, UK. Currently he is working on RF and Microwave circuits and devices 